\title{
Trochanteric Fractures Treatment Results via Gamma Nail: Experimentation Based on a Series of 130 Cases at Ibn Tofail Hospital
}

\author{
Coulibaly L*, Madhar M, Chafik R, ElHaoury H, Najeb Y
}

Trauma Department - Orthopaedics Ibn Tofail University Hospital, Marrakech - Morocco

DOI: $10.36347 /$ sasjs.2020.v06i07.004

| Received: 28.06.2020 | Accepted: 06.07.2020 | Published: 16.07.2020

*Corresponding author: Lassana Coulibaly

Abstract

Original Research Article

The frequency of trochanteric fractures rises in parallel with the ageing of the population, and with the degree of osteoporosis. Osteosynthesis using gamma nail has become the surgical technique that best ensures a satisfactory management of these fractures. In a retrospective study, we report the characteristics of 130 patients treated for trochanteric fractures in the Department of Traumatology-Orthopedics of the Ibn Tofail University Hospital of the Mohamed VI University Hospital Center of Marrakesh, over a period of 5 years from 2014 to 2018. The mean age of patients was 63 years with a male predominance $(76.2 \%)$. The main causes of fracture were simple falls in $50 \%$ of cases, and motor accidents in $23.1 \%$ of cases. In $62.3 \%$ of cases, an underlying condition was present. All patients underwent standard gamma nail surgery. The results were assessable in only 80 patients, and were encouraging, with a rate of good to excellent results of $68.7 \%$. We were able to identity 15 postoperative complications, that is in $18,75 \%$ of cases, going back 8.5 months on average after treatment. Our findings bear resonance with several other studies. Trochanteric fractures constitute a public health problem, and their management requires a multidisciplinary approach.

Keywords Trochanteric fractures - Osteosynthesis - gamma nail.

Copyright @ 2020: This is an open-access article distributed under the terms of the Creative Commons Attribution license which permits unrestricted use, distribution, and reproduction in any medium for non-commercial use (NonCommercial, or CC-BY-NC) provided the original author and source are credited.

\section{INTRODUCTION}

Fractures of the Trochanterian massif are considered to be one of the most public health problems that the elderly faced. They form the most dramatic and feared fracture group for elders, thus provoking major causes of mortality, morbidity and loss of autonomy. Their epidemiological profile is moving towards an almost exponential increase. Related to the aging of the population, caused mainly by minimal trauma such as a banal fall concerning the elderly and violent trauma for the young, they occur three times out of four concerning a woman because of post-menopausal osteoporosis. The goal of treating these fractures is to allow patients to quickly regain their independence in order to improve survival. The gamma nail is one of the implants designed to best satisfy these conditions by using a closed foyet intramedullary fixation method with early loading.

\section{PATIENT AND METHODS}

This is a non-randomized, retrospective descriptive study of 130 cases of trochanteric massif fractures collected over a period of 2014 to 2018. Clinical, para-clinical and evolutionary information was collected from patient records and follow-up in consultation based on an operating sheet. We classified our patients by age categories recommended by the World Health Organization: young 59 years, geriatrics (60-74 years), old (75-89 years), and older adults $>90$ years, and adopted the classification of Ramadier modified by Decoulx and Lavarde[1] which uses a standard hip x-ray to classify fractures and Singh's classification[2] to express the degree of osteoporosis. The functional results were judged on the basis of the functional rating of Merle d'Aubigné [3] based on the study of pain, mobility and hip stability. The inclusion criteria consisted of at least three months of follow-up with a complete clinical and radiological result. However, we were limited because these elderly patients with fractures could not be followed for a long time. Most of them didn't come back to see us once the fracture is healed. It also became more and more difficult during a longer follow-up, as the system of appointments for consultation through the internet and transport was not affordable for everyone. This confluence of reasons has given rise to many patient records not to be exploitable. Despite these challenges, the results could be evaluated in only 80 patients who were representative of all patients operated in terms of age and fracture type. Statistical analysis of the data was performed by SPSS21 software. 


\section{RESULTS}

Epidemiologic data the average age of our patients is 63 years with extremes of (19 - 97 years) of which $38.46 \%$ gerontins (60-74 years) (Figure 1). The series includes $76.2 \%$ of males and $23.8 \%$ of females, among whom more gerontins were found at $54.8 \%$ and among males, the majority was 59 years old found at
$38.4 \%$ (Figure 2). 55.4\% of patients had a fracture on the left side, $44.6 \%$ on the right side. The main etiology is simple fall in $50 \%$ of patients, followed by road accidents in $23.1 \%$ of cases. The young people of 59 years had more strokes at $46.7 \%$, more Work Accidents (AT), and sports accidents.

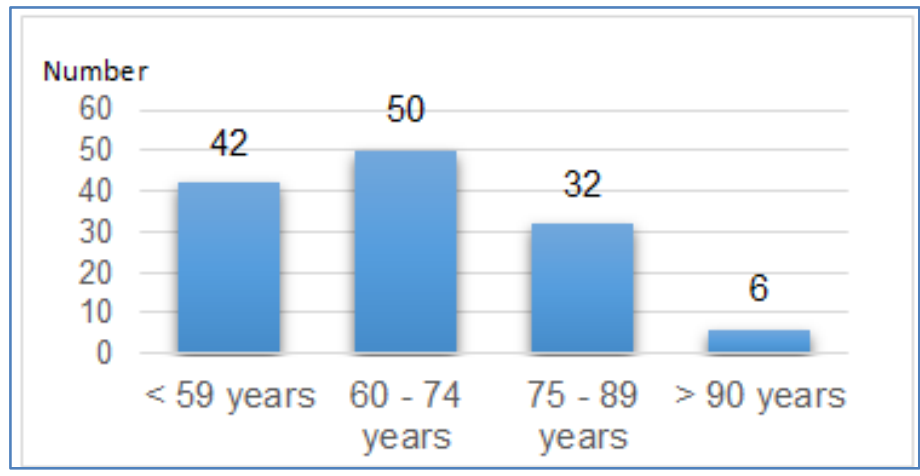

Fig-1: Breakdown of patients into age groups

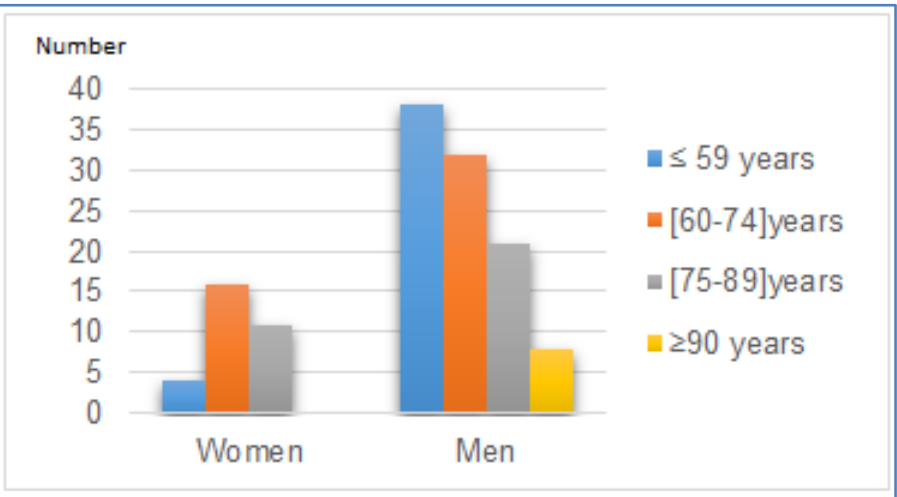

Fig-2: Breakdown of different age categories in every sex.

b. X-ray and clinical data: The consultation time was an average of 6 days, with 87 patients seeing the same day of the trauma or $66.9 \% .31$ had associated lesions of $23.8 \%$ and 81 cases of $62.3 \%$ had associated defects dominated by diabetes, hypertension and cataracts. According to the classification of Ramadier modified the fractures per trochanterians simple $(46.2 \%)$ and the fractures trochanterodiaphysaire $(23.8 \%)$ are the most frequent in our series.
Unstable fractures per trochanteric complex, trochanterodiaphyseal, subtrochanteric and intertrochanteric fractures represent 70 cases or $53.8 \%$. According to Singh's classification, the predominance of index 4 and 6 for the degree of osteoporosis was found in 65 cases or $50 \%$ (Figure 3 ).

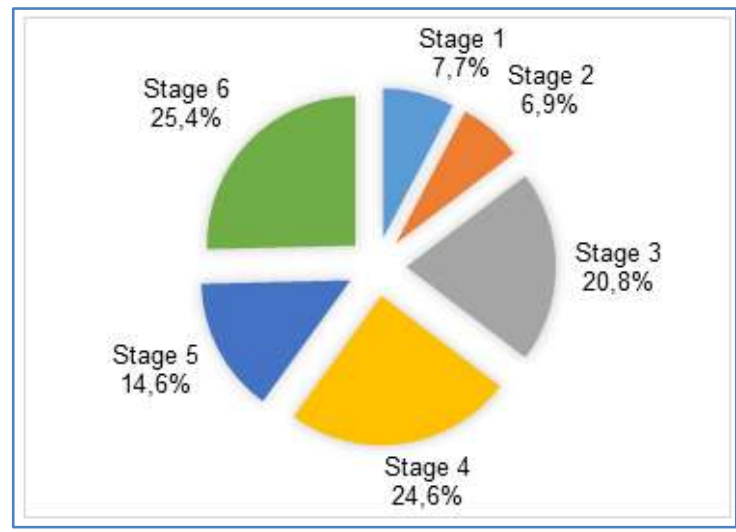

Fig-3: Distribution of osteoporosis singh classification 
C-Treatment: All of our patients have had standard gamma nail osteosynthesis. The average intervention time was 9 days with extremes ranging from the same day of trauma to 30 days. After hospitalization, all our patients were systematically put on glued traction, all benefited from thromboembolic disease prophylaxis with low molecular weight heparin, and analgesic treatment.73, 9\% of the patients were operated under local anesthesia and $20.8 \%$ under general anesthesia. Antibiotic prophylaxis was started 15 to $30 \mathrm{~min}$ before surgery and continued for 48 to 72 hours. Post-operative $x$-rays were routinely taken within 24 hours of the procedure and included x-rays of the hip from the front and from the side. Blood loss was determined by the volume collected in the suction drains. The average was $150 \mathrm{cc}$. A blood transfusion was required during or after surgery in 34 patients $(26.2 \%)$, with an average of one unit. The mean time from surgery to discharge was 4 days with extremes ranging from 1 to 45 days. The average length of hospitalization was about 15 days with extremes ranging from 3 days to 90 days.

d. Post-operative evolution: Anatomical and functional results could be analyzed in 80 patients. The mean decline in the series was 8.5 months with extremes of 1 and 20 months. Early complications included: three superficial skin infections, temporospatial confusion, deep vein thrombosis, functional intestinal obstruction, and peripheral neurogenic syndrome. The secondary and late complications included two sepsis on osteosynthesis material which necessitated revision surgery with removal of the material (Photo 1), three vicious calluses, one in coxa valga, two in coxa vara, and a scan of the cephalic screw. According to Merle d'Aubigné, the functional results were excellent and good in $68.7 \%$ of cases (Table I).

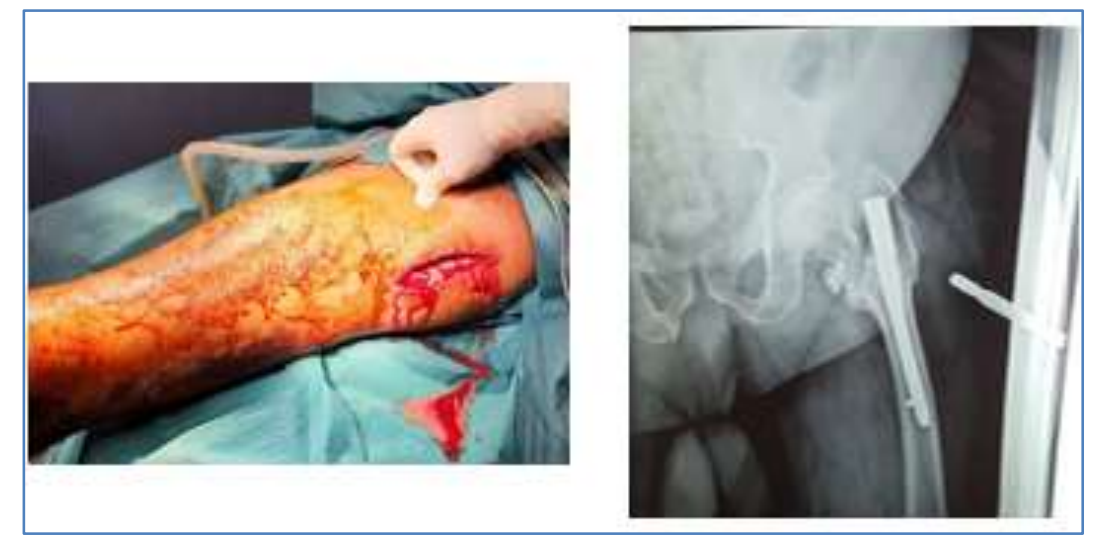

Photo-1: Sepsis on material that required a recovery

Table-I: Functional results according to Merle d'Aubigné

\begin{tabular}{|l|c|}
\hline Results & Percentage (\%) \\
\hline Excellent & 28,7 \\
\hline Good & 40 \\
\hline Way & 22,85 \\
\hline Bad & 8,39 \\
\hline
\end{tabular}

\section{DISCUSSION}

The average age in our series is lower than that in the literature $[4,5,6]$ because of their older population and their life expectancy which is higher than ours. There is a predominance of the male sex, which is not consistent with these same series where the female sex is dominant, which is explained by postmenopausal osteoporosis and the greater longevity of women compared to men. In all the series $[5,6,7,8]$ the authors concluded that minimal trauma (simple fall) is the most frequent etiology encountered in this type of fracture in elderly subjects. This can be explained by the existence of risk factors for falls concerning the elderly population, represented by environmental conditions not always well adapted to age, physical conditions related to senescence and associated pathological conditions or defects, which were frequent in all series $[4,8,9]$, which is explained by the age of patients with fractures of the trochanteric massif, which is often over 60 years old. They are a vital prognostic factor that makes this pathology so serious. Their decompensation would lead to the death of the elderly subject or poor functional results leading to a loss of autonomy. In our series, unstable fractures predominate, and this is the case for the majority of series $[4,10]$. In contrast to the other series where stages 2, 1 and 3 are dominant, stages 6,4 of osteoporosis also predominate [9]. This can be explained by the frequent occurrence of fractures of the trochanteric massif in men in our series and in postmenopausal women in the literature. Epidemiologically, the majority of women are exposed to the risk of osteoporosis because they have a longer life expectancy and their bone consistency decreases at menopause [11]. The recommended treatment of 
trochanteric fractures involves surgical treatment with closed or open osteosynthesis. Open osteosynthesis has the theoretical advantage of allowing an anatomical reduction with the disadvantage of additional devascularization of the fracture site and an increased risk of hemorrhage and sepsis. The advantages of closed osteosynthesis are the rapidity of the operation and above all the low hemorrhagic nature with respect to the fracture hematoma, which is favorable to consolidation. The influence of surgical delay on the mortality and morbidity of hip fracture patients has been the subject of numerous studies with controversial results. However, Moran [12], in a monocentric prospective study of patients with an average age of 80 years, concluded that in the absence of acute comorbidity, a delay of no more than 4 days does not affect mortality at 30 days or 1 year, morbidity or length of hospital stay. On the other hand, beyond 4 days, the mortality rate is multiplied by 2.5 . In our series we have observed an average intervention time of 9 days, which is relatively long, which can be explained by the low socio-economic level of most of our patients who are forced to buy the osteosynthesis equipment and the interdepartmental advice during pre-anesthetic visits, especially for patients with several defects. Locoregional anesthesia is the most used in our series and in foreign series [4, 8, 9], but the choice of the type of anesthesia remains a multifactorial decision per individual, with an analysis, for each technique, of the benefit and the risk. Concerning blood loss, our results are similar to other series confirming the low hemorrhagic character of Centro medullary osteosynthesis [8]. The average decrease remains insufficient, which is explained by the low socioeconomic level of most of our patients and the difficulties of transport. However, we have had good anatomical and functional results similar to most of the series in the literature $[4,8,13]$.

\section{CONCLUSION}

The results found in our series are similar to those of most series in the literature. They show that trochanteric fractures are a public health problem, and their management must be multidisciplinary. The gamma nail is a technique that can be applied in almost all of these fracture cases without opening the shaft, and its mechanical strength allows early loading in most cases, with the knowledge that this technique is simple to practice and learn. The prevention of falls and osteoporosis must be the first steps and the follow-up of fractured patients must be imperative in order to avoid the decompensation of defects and the occurrence of decubitus complications.

\section{REFERENCE}

1. Pibarot V, Bejui-Hugues J. Fractures du massif trochantérien (prothèse fémorale exceptée). Encycl. Méd-Chir, Techniques chirurgicales, OrthopédieTraumatologie. 2001:44-620.

2. Singh M, Nagrath A R, Maini P S. Changes in Trabecular Pattern of the Upper End of the Femur as an Index of Osteoporosis. J Bone Joint Surg Am. 1970;52:457-67.

3. Merle d'Aubigné F. Cotation chiffrée de la fonction de la hanche. Revue de chirurgie orthopédique. 1970;56:481-86.

4. Mnif H, Koubaa M, Zrig M, Trabelsi R, Abid A. Elderly patient's mortality and morbidity following trochanteric fracture. A hundred cases prospective study. Orthopaedics \& Traumatology: Surgery \& Research. 2009; 95:505-10.

5. Loubignac F, ChabasJ-F. A newly designed locked intramedullary nail for trochanteric hip fractures fixation: Results of the first 100 Trochanteric TM implantations. Orthopaedics \& Traumatology: Surgery \& Research. 2009; 95:139-44.

6. Alvarez-Nebreda M L, Vidan M T, Serra J A. Hip fracture management and outcomes in Spain. European Geriatric Medicine. 2010;1:108-11.

7. Lonnroos E, Kiviranta I, Hartikainen S. Hip fracture management and outcomes in Finland. European Geriatric Medicine. 2010;1:101-3

8. Verettas J, Ifantidis P, Chatzipapas N, DrososI ,Xarchas C, Chloropoulou P, KazakosI, Trypsianis G, Ververidis A. Systematic effects of surgical treatment of hip fractures: Gliding screw-plating vs intramedullary nailing Injury Int $\mathbf{J}$ Care Injured. 2010;41:279-84.

9. Vidyadhara S, Rao K. One and two femoral neck screws with intramedullary nails for unstable trochanteric fractures of femur in the elderlyRandomised clinical trial. Injury Int J Care Injured. 2007; 38:806-14.

10. Yaozeng X, Dechun G, Huilin Y, Guangming Z, Xianbin W. Comparative study of trochanteric fracture treatedwith the proximal femoralnail antirotation and the thirdgeneration of gamma nail. Injury Int J Care Injured. 2010;41:986-90.

11. Curran D, Maravic M, Kiefer P, Tochon V, Fardellone P. Epidemiology of osteoporosis-related fractures in France: a literature review. Joint Bone Spine. 2010 Dec 1;77(6):546-51.

12. Moran CG, Wenn RT, Sikand M, Taylor AM. Early mortality after hip fracture: is delay before surgery important? JBJS. 2005 Mar 1;87(3):483-9.

13. Mansour L. Prise en charge des fractures trochanteriennes à l'hopital El Hassani de Nador (Doctoral dissertation, Thèse Doctorat Médecine, Casablanca). 